\title{
Management-intensive Grazing Affects Soil Health
}

\section{Supplemental Information}

\author{
Casey Shawver ${ }^{1}$, James A. Ippolito ${ }^{1 *}$, Joe Brummer ${ }^{1}$, Jason Ahola², and Ryan Rhoades ${ }^{2}$ \\ 1 Department of Soil and Crop Sciences, Colorado State University, Fort Collins 80523, USA \\ 2 Department of Animal Sciences, Colorado State University, Fort Collins 80523, USA \\ *Corresponding author: Jim.Ippolito@colostate.edu
}

The following information is provided to the reader for understanding the materials and methods utilized for determining the 11 soil indicators used in the Soil Management Assessment Framework (Andrews et al., 2004).

\section{$\underline{\text { Microbial biomass C }}$}

The microbial biomass protocol used was a modified version of the fumigation method by Allison (2008). For each replicate, two $10 \mathrm{~g}$ sub-samples of 8-mm field moist (oven-dry equivalent) soil were utilized for fumigation and non-fumigation extractions. Non-fumigated samples were shaken for one hour with $50 \mathrm{ml}$ of $0.5 \mathrm{M} \mathrm{K}_{2} \mathrm{SO}_{4}$, and then filtered through Whatman 2V folded filter paper. Fumigated samples were placed in $50 \mathrm{ml}$ glass beakers and placed in a vacuum desiccator along with a 200-mL beaker containing $20 \mathrm{ml}$ of non-ethanol containing chloroform and several boiling chips. A vacuum was attached to the desiccator, and the desiccator evacuated until the chloroform boiled; the desiccator was then vented. This process was repeated three more times with no venting after the last boiling. The desiccators were covered with a black garbage bag for four days to keep light out in order to prevent 
chloroform degradation. Afterward, the desiccators were vented, and a vacuum was drawn for 2 minutes to remove excess chloroform. This process was repeated 5-10 times. Following the chloroform evacuation step, the samples were extracted following the same protocol as above. A $4 \mathrm{~mL}$ subsample of the (non) fumigated filtrate was diluted with $36 \mathrm{ml}$ of deionized (DI) water and then analyzed for total dissolved C using a Shimadzu TOC-L (Shimadzu Scientific Instruments, Inc). The difference between $\mathrm{C}$ in the fumigated and non-fumigated samples was considered the chloroform-labile C pool (EC), and is proportional to microbial biomass C (C): $C=E C / k E C$ where $k E C$ is soil-specific but was (and often is) estimated as 0.45 (Beck et al., 1997).

\section{$\underline{\text { Water stable aggregates }}$}

This procedure was based on the method of Kemper and Rosenau (1986) using the 8-mm sieved, air-dried soil. A $100 \mathrm{~g}$ sub-sample was placed on top of a nest of 23-cm diameter sieves comprised of 2.0, 1.0, 0.5, and 0.25-mm screen sizes. The sieves were locked into a metal holder, completely immersed in a water column, and the holder connected to a modified Yoder sieving machine. The machine was set to 30 strokes per minute for 5 minutes, after which the sieves were removed, the soil removed from each sieve with water, and collected in pre-weighed $23 \mathrm{x}$ $33 \mathrm{~cm} \mathrm{Al}$ pans. The pans were placed in an oven at $105^{\circ} \mathrm{C}$ until all the water evaporated, and then weighed to determine percent total aggregates.

\section{Potential mineralizable N (PMN)}

Potentially mineralizable nitrogen (PMN) was determined using a 28-day aerobic incubation (Curtin and McCallum, 2004). Briefly, a $10 \mathrm{~g}$ sub-sample of the air-dried, 2-mm sieved soil was shaken for 30 minutes with $2 \mathrm{M} \mathrm{KCl}$, then filtered. These results represented 
baseline inorganic $\mathrm{N}$ (e.g., $\mathrm{NH}_{4}-\mathrm{N}+\mathrm{NO}_{3}-\mathrm{N}$ ) and were determined colorimetrically using a Lachat Flow Injection System (QuikChem 8500 Series 2 FIA). Another $30 \mathrm{~g}$ sub-sample of airdried soil was placed into a $50 \mathrm{ml}$ beaker, the soil gently packed to a uniform bulk density of 1.0 $\mathrm{g} \mathrm{cm}^{-3}$ and adjusted to $60 \%$ water-filled pore space with DI water. The beaker was then placed in a quart-sized glass mason jar to which a small amount of water was added at the bottom to maintain $100 \%$ relative humidity. Jars were incubated in the dark at room temperature for 28 days, opening every seven days to allow for air exchange. After the 28-day incubation period, a 10 g sub-sample was removed, extracted with $2 \mathrm{M} \mathrm{KCl}$, filtered, and analyzed for inorganic $\mathrm{N}$ as above. Soil moisture content was determined on a separate sub-sample to correct for weight. Potentially mineralizable $\mathrm{N}$ was calculated by subtracting the baseline from 28-day mineralized inorganic $\mathrm{N}$ concentrations.

$\mathrm{pH}$ and EC

Soil pH and electrical conductivity (EC) were determined using a 1:1 (soil:solution) extraction (Rhoades, 1996; Thomas, 1996). Briefly, 20 g of air-dried, 2-mm sieved soil, and 20 $\mathrm{mL}$ of DI water were placed into $50 \mathrm{~mL}$ centrifuge tubes and shaken for 2 hours. Afterward, the $\mathrm{pH}$ was directly measured in the mixture. Mixtures were then centrifuged to separate the solution from the solid phase. The solution was gently poured into an EC meter for EC determination.

\section{$\underline{\text { Soil-Test P and K }}$}

Olsen-extractable $\mathrm{P}$ and $\mathrm{K}$ were determined by shaking $2 \mathrm{~g}$ of air-dried, 2-mm sieved soil with $40 \mathrm{ml}$ of $0.5 \mathrm{M} \mathrm{NaHCO}_{3}$ (adjusted to $\mathrm{pH}$ 8.5) solution for 30 minutes (Olsen et al., 1954). The solution was filtered through Whatman $2 \mathrm{~V}$ folded filter paper, allowed to sit overnight to 
allow for loss of $\mathrm{CO}_{2}$, and then diluted ten-fold with DI water before analysis via inductivelycoupled plasma-optical emission spectroscopy (ICP-OES).

Total C, Inorganic C, and Organic C

A $15 \mathrm{~g}$ sub-sample of 2-mm sieved soil was placed in a $20 \mathrm{~mL}$ plastic scintillation vial containing two metal rods. The vials were tightly packed into a $2 \mathrm{~L}$ plastic bottle and placed on a roller mill (Bailey Mfg., Inc., Norwalk, IA) for five days to allow metal rods to pulverize soil and create a fine powder. This powder was analyzed for total soil C content using a dry combustion LECO Tru-SPEC Elemental Analyzer (Leco Corp., St. Joseph, MI) (Nelson and Sommers, 1996). The powder ground soil was then analyzed for inorganic C, determined via the modified pressure calcimeter method (Sherrod et al., 2002). Soil organic C (SOC) was indirectly determined by subtracting inorganic $\mathrm{C}$ from the total $\mathrm{C}$ content.

\section{$\underline{\text { Soil Texture }}$}

This analysis was outsourced to the Colorado State University Soil, Water, and Plant Testing Laboratory (Fort Collins, Colorado, USA). The laboratory utilized the hydrometer method to determine the percentage of sand, silt, and clay, and corresponding texture classification (Ashworth et al., 2001).

\section{ß-Glucosidase Activity (BG)}

The procedure used was a modified method published by Green et al. (2007). Briefly, $1 \mathrm{~g}$ of air-dried, 2-mm sieved soil was added to a $50 \mathrm{~mL}$ Erlenmeyer flask; each sample was duplicated along with an equal set of controls and a single blank. Next, $4 \mathrm{~mL}$ of modified universal buffer (MUB) adjusted to $\mathrm{pH} 6.0,0.25 \mathrm{~mL}$ of toluene, and $1 \mathrm{~mL}$ of $0.05 \mathrm{M} \rho$ nitrophenyl-ß-D-glucopyranoside (PNG) solution was added to the flasks. It is important to note 
that the PNG was not added to the set of controls until after the incubation process. The sample was swirled and stoppers were placed on the flasks, followed by incubation at $37^{\circ} \mathrm{C}$ for 1 hour. The reaction was stopped by adding $1 \mathrm{~mL}$ of $0.5 \mathrm{M} \mathrm{CaCl}_{2}$ and $4 \mathrm{~mL}$ of $0.1 \mathrm{M}$ Tris (hydroxymethyl) aminomethane (THAM) buffer solution ( $\mathrm{pH} ~ 12)$ followed by flask swirling. The soil suspension was filtered through Whatman No. 2 filter paper. The samples were diluted five-fold using $1 \mathrm{~mL}$ of filtrate and $4 \mathrm{~mL}$ of $0.1 \mathrm{M}$ THAM prior to analysis. A standard curve was created using solutions of increasing $p$-nitrophenol concentrations $(0,10,20,30,40$, and 50 ug $\mathrm{L}^{-1}$ ). These standards also contained $1 \mathrm{~mL}$ of $0.5 \mathrm{M} \mathrm{CaCl}_{2}$ and $4 \mathrm{~mL}$ of $0.1 \mathrm{M}$ THAM buffer solution to mimic the sample solution matrix. A yellow color was developed, with color intensity measured on a Genesys 10S UV-VIS spectrophotometer at $410 \mathrm{~nm}$. 